\title{
Hepcidin as a Potential Biomarker for Diagnosis of Anaemia
}

\section{Anemi Teşhisi Için Potansiyel Bir Biyobelirteç Olarak Hepsidin}

\author{
Short title: Hepcidin as a Biomarker for Anaemia \\ Zainab H. Fathi, Jehan A. Mohammad, Zaid M. Younus, Sameer M. Mahmood \\ Department of Pharmacognosy and Medicinal Plants, College of Pharmacy, University of \\ Mosul, Mosul, Iraq
}

\section{Corresponding Author Information}

Zainab H. Fathi

009647738502141

zainabh@uomosul.edu.iq

https://orcid.org/0000-0003-0327-0914

10.04 .2021

26.08 .2021

04.10 .2021

\begin{abstract}
There are several blood-based markers to assess iron stores, but they all have some limitations. Hepcidin, a low-molecular-weight peptide hormone, is mainly produced by liver. It is the main regulator of iron homeostasis through prevention iron release into plasma from absorptive enterocytes and macrophages. The objective of this review is to critically assess existing data on potential role of hepcidin in diagnosis, particularly the (pre) analytical implications of the hepcidin measurement. There is a well-known causative correlation between hepcidin and iron deficiency. Therefore, hepcidin is considered to be a promising marker in the assessment of iron status, particularly in patients with diagnostic dilemma, such as patients with chronic renal disease and infants. The clinical implications of this peptide hormone in diagnosis of other diseases have been expanded in the recent studies, including elevated hepcidin levels in neoplastic diseases, sepsis and inflammation. The potential role of hepcidin in diagnosis is controversial in the various types of iron deficiency because data is conflicting (as in anaemia of chronic disease) or limited (as in infants), whereas in the case of hereditary haemochromatosis $(\mathrm{HH})$, it has been proposed that hepcidin may be used for stratification of molecular testing, or to improve the frequency of phlebotomy, however this issue still needs to be investigated. Due to lack of a clinically approved test, the medical application of this peptide as a biomarker in diagnosis is restricted. Recently, assays have been developed to determine hepcidin levels in serum and urine, facilitating the future use of hepcidin in research and clinical practice.

Keywords: Hepcidin, Iron deficiency, Anaemia.

Introduction

Biologically important hemoproteins like haemoglobin and myoglobin contain iron as an essential element. Therefore, iron homeostasis is critical for normal erythropoiesis and other cellular processes. ${ }^{(1)}$ As there is no regulatory mechanism for excreting iron from the body apart from losses due to menstruation and other bleeding processes, dietary iron uptake and status of internal iron stores are the major regulator of constant iron balance. ${ }^{(2)}$ Anaemia
\end{abstract}


represents a worldwide public health problem with symptoms caused either by nutrients deficiency to hereditary changes in absorption and metabolism of iron. ${ }^{(3)}$ Although different forms of enzymes and proteins have been involved in iron transporting, it was found that iron homeostasis is tightly controlled via a hepatic-produced hormone, hepcidin, by tightly affecting the production of erythrocytes. Therefore, Hepcidin's discovery in 2001 changed our understanding of iron problems, and its measurement should help with diagnosis and treatment. ${ }^{(4)}$ High levels of hepcidin inhibit intestinal absorption and macrophage recycling of iron, resulting in iron-restricted erythropoiesis and anaemia. In contrast, low levels of hepcidin stimulate the supply of iron to the bone marrow for haemoglobin $(\mathrm{Hb})$ synthesis and production of erythrocytes. ${ }^{(5)}$ Erythropoiesis, after erythropoietin therapy or hemorrhage, inhibits hepcidin by decreasing transferrin saturation and releasing of erythroblast and the hepcidin inhibitor (erythroferrone). On the other hand, decreased erythropoiesis, reducing iron consumption, increasing transferrin saturation and stimulating hepcidin transcription. ${ }^{(6)}$ Hepcidin acts via binding with a ferroprotein, a multipass membrane protein and thus inhibiting the iron efflux into the plasma. ${ }^{(7)}$ Many studies confirms the relationship between hepcidin production and pathogenesis of iron-linked diseases. ${ }^{(8-10)}$ Elevated hepcidin levels may associated with anemia unresponsive to treatment with iron, while decreased plasma hepcidin may result in excess iron in the circulation with tissue-iron deposition. ${ }^{(10,11)} \mathrm{In}$ addition, higher hepcidin levels have been involved in many clinical conditions, such as inflammation, neoplastic diseases, and sepsis. ${ }^{(2,12,13)}$ In future, the dependence on proven detection methods will enhance the possibility of hepcidin use as a novel biomarker in clinical practice.

\section{Hepcidin synthesis and regulation}

Hepcidin is a small cationic peptide of 25 amino acids and mass of $2.7 \mathrm{kDa}$. Because of its antifungal and antibacterial activities, hepcidin was first identified as a hepatic produced antimicrobial protein. ${ }^{(14)}$ Then, the antimicrobial activity and origin of hepcidin in the liver, reflecting its new official nomenclature Although the major source of hepcidin synthesis is in the liver, but recent findings also revealed extra-hepatic synthesis of hepcidin in the kidney, heart, retina, alveolar cells, bacteria-activated neutrophils and macrophages, pancreatic $\beta$-cells and adipocytes. ${ }^{(15)}$ However, substantially lower expression of hepcidin gene has been observed in these tissues compared to the hepatic production and its relative importance remains unknown.

Hepcidin peptide in human is encoded by the hepcidin antimicrobial peptide (HAMP) gene which present in chromosome 19. Hepcidin encoded as a preprohepcidin protein, 84 amino acid precursor, which subsequently converted to the bioactive hepcidin peptide by two sequential cleavages in the cytoplasm of hepatocyte and in the blood. ${ }^{(1)}$ After hepatic production, hepcidin reaches blood circulation and provides widespread in the tissues. All hepcidin isoforms 20, 22 and 25 are excreted in urine. Hepcidin-20 and 22 are regarded the degradation byproducts of hepcidin. ${ }^{(2)}$

As indicated by NMR spectroscopy studies, human hepcidin's molecular structure consists of one beta sheet in the peptide backbone, which has an eight cysteine loop formed by four disulfide bonding molecules. It is considered necessary to carry out biologic activities with cysteine and N-terminal amino acids which form the copper and nickel binding (ATCUN) motif. ${ }^{(14)}$ Hepcidin works in three primary iron-metabolism target cell types, namely enterocytes, hepatocytes and reticuloendothelial macrophages, which considered the three primary plasma iron sources (Transferrin-Fe2+). The hemoglobin incorporated in the erythrocytes is attributed approximately $66 \%$ iron in the human body. Macrophages ingest senescent erythrocytes, then releasing iron in blood or storing it as ferritin. Similarly, intestinal epithelial cells absorb all heme and non-heme iron, thus resulting in iron released in plasma or iron stored as ferritin. Endocytosis is used in cells expressing transferrin receptors 
to get transferrin from the bloodstream. ${ }^{(2)}$ This iron is used for erythropoiesis by bone marrow erythroid cells, while it is used for storage by liver cells. Ferroportin is the iron exporter across membrane responsible for iron efflux from tissue to circulation for use in erythropoiesis. Hepcidin binds with ferroportin and induces an adverse effect on erythropoiesis by stimulating the uptake and then degradation of ferroportin. ${ }^{(7,10,16)}$

\section{Pathogenesis of iron metabolism disorders}

Iron deficiency diseases are the first type of iron metabolism disease. Iron deficiency conditions are associated with reduction of ferritin, reduced serum iron and transferrin saturation, microcytosis, and hypochromia. However, in certain cases, like newborns, inflammatory diseases or severe renal disorders using erythropoietin-stimulant medications, the diagnosis of iron deficiency diseases depending on these laboratory results is difficult. Therefore, hepcidin may be an important biomarker in these situations.

\section{Hepcidin in clinical diagnostic}

Plasma levels of hepcidin are well correlated with plasma ferritin in healthy persons. Moreover, serum hepcidin concentrations are significantly reduced in iron deficit patients. ${ }^{(17)}$ Hepcidin is an acute phase protein of type II, with elevated hepcidin correlating with higher serum ferritin in severe inflammations. ${ }^{(18,19)}$ In comparison with traditional biomarkers, hepcidin with ferritin have significant value in diagnosis different forms of iron diseases. ${ }^{(20)}$ In addition to importance of ferritin as a reliable biomarker for iron storage, the pathogenesis of many iron conditions like ACD or haemochromatosis includes variations in hepcidin levels. Thus, hepcidin determination may provide an indicator on aetiology of iron diseases and enable diagnosis prior to depletion of iron stores. ${ }^{(17)}$ The diagnostic role of hepcidin in situations that have a diagnostic difficulties with traditional biomarkers is outlined below

\section{Hepcidin in infants with iron deficiency anaemia (IDA)}

Infants with iron-deficient erythropoiesis or latent iron deficiency (LID) had difficulty in diagnosis with the conventional iron laboratory parameters. In these infants, ferritin is not an ideal indicator of anaemia so that transferrin levels are often low in infants. In addition, there is no diagnostic benefit for serum transferin receptor (sTfR). ${ }^{(21)}$ In order to avoid permanent changes of neurodevelopment, early diagnosis of iron deficiency in children is necessary. ${ }^{(22)}$ The content of reticulocyte haemogiobin $(\mathrm{CHr})$ represented the availability of iron for incorporation in the bone marrow just a few days earlier. The best iron indicator for infants seems to be $\mathrm{CHr} .{ }^{(23)}$, but there is still limited availability to this test. Even before anemia occurs, hepcidin has been recommended to diagnose children with iron deficiency. ${ }^{(20)}$ Genetic diseases are rarely resulted in iron deficiency anaemia in young children. Ironrefractory iron deficiency anaemia is a genetic disease marked by inherited hypochromic microcytic anaemia, typically unresponsive to oral intake of iron, and partially improved with intravenous intake of iron. In Iron-refractory iron deficiency anaemia patients, mutations are heterogeneous, including splicing, frame-shift, nonsense and missense mutations in TMPRSS6, an encoding gene for matriptase-2. Normally, matriptase- 2 supresses the expression of hepcidin. Mutation in this gene contributes to improperly elevated hepcidin levels in human and animals, making intestinal absorption of iron impossible. ${ }^{(24-26)}$ Early diagnosis of iron deficiency diseases is impossible with the traditional biomarkers and is required in order to use the appropriate iron therapy (parenteral). Therefore, hepcidin quantitation can give a diagnostic method for iron-refractory iron deficiency anaemia to direct genetic testing.

Hepcidin can identify iron deficiency prior to development of anaemia develops, generating a potential identification method in infants. Nevertheless, no trials have yet evaluated the application of hepcidin. Moreover, trials in infants revealed no correlation between prohepcidin and iron status. ${ }^{(27-29)}$ Since infants cannot control intestinal absorption of iron, it is likely that it would not have any diagnostic benefit for hepcidin, because hepcidin is the 
regulator of iron absorption. ${ }^{(30)}$ Trials are required to explain why iron-refractory iron deficiency anaemia (IRIDA) does not respond to oral therapy of iron. Without inflammation, IRIDA may be suspected in patients with iron deficiency and elevated serum hepcidin. Moreover, another study demonstrated that in elderly anaemic individuals with concomitant inflammation, hepcidin is not better than ferritin in diagnosis of iron deficiency. In these patients, hepcidin has a significant positive association with ferritin and C-reactive protein. ${ }^{(31)}$ Unfortunately, there are no trials that have examined hepcidin in diagnosis of iron deficiency.

\section{Hepcidin in anaemia of chronic disease with or without iron deficiency anaemia}

Higher levels of serum hepcidin are crucial for pathogenesis of chronic disease anaemia

(ACD). The ACD is identified by cytokines-induced macrophage iron retention, which is partly mediated by elevated serum hepcidin, triggered by interleukin- $6 .{ }^{(26,32)} \mathrm{ACD}$ is associated with normochromic normocytic anemia and reduced reticulocyte numbers, accompanied with erythropoiesis inhibition. ${ }^{(32)}$ It is difficult to diagnose iron deficiency in ACD patients because coexisting blood losing, drugs intake or inborn defect in $\mathrm{Hb}$ synthesis could have an effect on them. Concerning to treatment, it is very important to differentiate between ACD with iron deficiency and ACD, where iron therapy is essential in the first case, but controversial and not currently recommended in the second. ${ }^{(32)}$ Ferritin and other biochemical markers of iron are influenced by acute phase reaction. Therefore, it is difficult to distinguish between ACDs with or without iron deficiency depending on serum ferritin. In both cases, reduced iron level and low saturation of transferrin are recognised. ACD patients with iron deficiency anaemia often have microcytes with seyere anaemia in comparison to those with ACD alone. ${ }^{(32)}$ The soluble transfer receptor (sTRR) is, newner marker, a truncated portion of the membrane receptor increases in deficiency of iron available for erythropoiesis. The sTfR/ferritin ratio could be helpful in differentiating ACDs with or without iron deficiency. However, this ratio is not commoniy used in clinical practice because of the lack of standardization of the sTfR assays. ${ }^{(21)}$ Hepcidin is controlled by inflammation, and also by iron in the body. ${ }^{(33)}$ Hepcidin levels may be able to distinguish between ACDs with or without iron deficiency depending on the predominant regulatory mechanism. Interestingly, increased production of cytokines like INF- $\gamma$ by lymphocytes and interleukin $1-\beta$ and 6 and TNF- $\alpha$ by macrophages reduces synthesis of endogenous erythropoietin, inhibits the erythropoiesis process, enhances serum levels of hepcidin, and, hence activates erythrophagocytosis. ${ }^{(34)}$ Serum hepcidin levels are considerably lower in iron deficiency patients compared to healthy subjects..$^{(17,35)}$ Hepcidin is raised by inflammation in anemia of chronic diseases. ${ }^{(36)}$ Hepcidin levels in urine have reveared to respond markedly better in acute phases after injection of lipopolysaccharide in healthy persons than serum ferritin. ${ }^{(19)}$ Hepcidin also may be more likely to be more susceptible to iron imbalances than ferritin or other biomarkers. This remains completely default. But, because hepcidin is involved in acute phase reaction, the utilization of hepcidin measurement is uncertain. Just few clinical trials have examined whether hepcidin levels have become a valuable biomarker for iron deficiency diagnosis in ACD patients with or without IDA. In initial trials, the predominant regulator for the hepcidin was deficient iron stores because serum hepcidin was low in IDA, irrespective of inflammation, and hence the possibility for a hepcidin cut-off could be established to distinguish ACD with or without IDA. ${ }^{(26,37,38)}$ Nevertheless, even ferritin differs considerably within the ACD subgroups with or without iron deficiency, rendering it difficult to understand a possible benefit additional to hepcidin compared to ferritin in inflammation. ${ }^{(26)}$

Till now, there are no trials establishing a definite limit for the IDA diagnosis. A study by Lasocki et al. ${ }^{(37)}$ identified an iron deficiency cut-off in patients with intensive care. Just 5 from 51 patients were suffered from iron deficiency (just 3 with concurrent inflammation). Recently, studies revealed the difficulty in distinguishing between ACD with and without iron deficiency depending on the serum hepcidin. Thomas et al. ${ }^{(39)}$ identified latent IDA, ID, ACD 
and ACD with IDA in anaemic patients, depending on ferritin index plot. ACD was not distinguished from ACD/IDA by hepcidin only. Nevertheless, Thomas et al. ${ }^{(39)}$ showed that combining hepcidin and $\mathrm{CHr}$ instead of ferritin index plot because hepcidin could react to the haematologic state more quickly than ferritin. Therefore, it is important to remember that the only rapid reaction of hepcidin seen to date is a rapid rise in the urine due to inflammation. ${ }^{(19)}$ As a result, more studies are required to establish the variation in hepcidin among ACD, IDA and ACD with IDA. Moreover, the importance of hepcidin measurement as a diagnostic marker needed to evaluate in patients with unclear IDA.

One proposed approach to predicting classical IRIDA is to normalize hepcidin to other iron markers, such as the ratio of transferrin saturation/log hepcidin or transferrin saturation/log Ferritin. ${ }^{(40)}$ Another study revealed that most severe IRIDA patients are biallelic TMPRSS6 mutations and, when unrecognized, the second allele may be genetically obscure. ${ }^{(41)}$ Generally, people with two allele mutations have a more severe phenotype and are less responsive to iron therapy than those with one allele mutation. ${ }^{(40)}$ Interestingly, many TMPRSS6 single nucleotide polymorphisms have been detected in blood donors to increase susceptibility to iron deficiency. ${ }^{(42)}$

\section{Hepcidin and iron deficiency in chronic renal disorder}

Erythropoietin-stimulating agents (ESA) produces a substantial rise in erythropoietic activity in chronic renal disorder, which is followed by a sharp increase in demand for bioavailable iron. Even with adequate store of iron in the body and intake of oral iron therapy, ESA can produce a reduction in iron levels and transferrin desaturation, leading to iron deficient erythropoiesis. $^{(21)}$ This represents the third obstacle in diagnosis of iron deficiency. Diagnosis of this disease is required to administer the appropriate dose of ESA or intravenous iron for optimal response. The iron deficiency is predicted by low ferritin, but ferritin is unpredictable because of common inflammation induced effects. ${ }^{(43)}$ The saturation of transferrin reduces with inflammation and variates with serum iron changes daily. Moreover, after several weeks from parenteral iron it is not interpretable (100\% saturation). In patients with inflammation, elevated ferritin and $\sim 20$ percent transferin saturation, functional iron deficiency may be suspected. Despite of transferrin saturation and ferritin are the major parameters in diagnosis of iron deficiency, but trials to find a better indices continues. ${ }^{(44,45)}$ The $\%$ of red hypochromic cells will recognise developing IDA, but for changes in this marker it takes long periods of iron deficient erythropoiesis. Reticulocyt number and $\mathrm{Hb}$ alteration can distinguish patients as "responding" or "unresponders". CHr appears to be a promising predictor for ESA dosage. ${ }^{(21,46)}$ Therefore, it appears worth to investigate the additional importance of hepcidin in this situation.

Hepcidin has recognized as a major determinant in the pathogenesis of anemia in patients with chronic kidney disease (CKD), and explains the disturbed metabolism of iron and ESA resistance. ${ }^{(47)}$ Hence, hepcidin may be an effective predictor for response and guidance for ESA or parenteral iron therapy. The majority of patients with an ineffective ESA response have functional iron deficiency which cannot be detected by saturation of transferrin or ferritin. ${ }^{(21)}$ These patients are hypothesized to have higher levels of hepcidin, thus expecting to be hyporesponsive and require higher doses of ESA. In CKD and haemodialysis, elevated hepcidin levels were identified. ${ }^{17,48-50)}$ Nevertheless, not only anemia or iron can affect hepcidin concentrations in CKD, but several other factors like hypoxia, inflammation and erythropoietin (endogenous or exogenous). ${ }^{(51)}$ Furthermore, hepcidin is negatively correlated glomerular filtration rate (GFR), contributing to elevated hepcidin levels due to a reduction in renal excretion. ${ }^{(49)}$ Peters et al. ${ }^{(52)}$ showed no considerable association between hepcidin-25 and eGFR. However, the same study revealed that hepcidin-25 and hepcidin-20 and -22 isoforms had an inverse correlation with eGFR. In control group, hepcidin-22 was less than the measurable value, but detectable in patients with CKD and haemodialysis. With exception 
of hepcidin-25, hepcidin-20 and -22 accumulated in renal failure. Nevertheless, these findings need to be verified by more trials. Another study showed that dialysis can clear hepcidin, but it increased to pre-dialysis levels before the next dialysis. ${ }^{(53)}$

Clinical trials evaluating the relevant of hepcidin in differentiating responder and hyporesponder to ESA are few. One study revealed no variation in the intensities of hepcidin levels between erythropoietin responsive and hypo-responsive patients. ${ }^{(54)}$ In dialysis patient, hepcidin is associated with anaemia that are compatible with a possible role for elevated hepcidin levels in renal anaemia. ${ }^{(49)}$ However, in the same study revealed an inverse correlation between hepcidin levels and the dose of erythropoietin, which reduce the relevant of hepcidin in predicting higher need for erythropoietin. Another study revealed that unresponsive patients have reduced serum hepcidin, but these findings may be biased because unresponsive patients obtained significantly higher doses of erythropoietin than responsive patients. ${ }^{(55)}$ Swinkels et al. ${ }^{(56)}$ recommend observing the initial hepcidin changes after a first dose of parenteral iron and/or erythropoietin, because a single dose will predict patient response prior to start the anaemia therapy. However, further trials are required to elucidate the potential role of hepcidin in diagnosis.

\section{Hepcidin and iron overload}

Iron-storage disorders are the second group of disorders of iron metabolism. Nevertheless, high ferritin concentrations do not have the lack the specificity to distinguish between genetic cases with a continuous deposition of iron and moderate iron overload due to disorders that affect the liver (for example viral hepatitis, alcoholic or non-alcoholic fatty hepatic disorder). ${ }^{(57,58)}$ The pathogenic factor in iron deposition of HH type 1 (HFE hemochromatosis), the main cause of hereditary iron overload, appears to be a reduced hepcidin production from the liver. ${ }^{(58)}$ Thus, the HFE C282Y homozygous induces decreased hepcidin expression, leading to deposition of parenchymal iron. Mutations of other genes involved in hepcidin activity, synthesis or regulation induce less common types of $\mathrm{HH} .{ }^{(59)} \mathrm{A}$ continues erythropoiesis decreases hepcidin in anemia associated with iron overload due to inactive erythropoiesis like thalassemia, which contributes to overload of iron in this disorder. As a result, producing severe reduction in hepcidin levels in types treated a non-blood transfusion methods. Whereas, hepcidin levels are higher in patients severely treated with blood transfusion compared with those treated with non-blood methods, because of elevated iron in the body and reduced erythropoiesis. ${ }^{(60)}$

It is not clear if a distinguishing role of hepcidin presents in cases of hyperferritinaemia. When there is a family incex case, the final diagnosis of HH is dependent on familial screening. ${ }^{(58)}$ Phlebotomy is the treatment for HH. Therapy is controlled by ferritin measurement since ferritin is correlated with iron levels in the liver and is a sensitive indicator of cirrhosis, albeit with the same non-specificity difficulty. Ferritin level $<50 \mathrm{mg} / \mathrm{l}$ is characterized as a consensus therapeutic target without relevant proof of its true significance. $^{(61)}$

The diagnosis is based on genotyping of HH. Hepcidin can be used as a direct measure for genetic iron overload, since hepcidin levels (or hepcidin to ferritin ratio) are reduced in $\mathrm{HH}$, but elevated in ferroportin disorders. ${ }^{(59)}$ Clinical characteristics like $\mathrm{Hb}$ (which is reduced in secondary iron overload and ferroportine disorder), family history (genetic disorder), concurrent disorder (such as, hepatitis and alcoholic) and age was used for the rational targeting of genes. To stratify genetic testing, hepcidin may then be applied. ${ }^{(59)}$ Therapeutically, hepcidin has a more significant use in HFE-haemochromatosis, specifically to determine need for phlebotomy. Firstly, hepcidin appears unsuitable to this objective, since abnormal levels of hepcidin trigger the disorder and are not sensitive for stores of iron. Actually, in spite of continuous phlebotomy, a persistent decrease in hepcidin results in a persistent increase in intestinal absorption of iron. Nevertheless, low hepcidin concentrations 
in serum and urine much further reduced with iron loss by flebotomy in HFE-related HH patients, and this reduction in hepcidin associated with a reduction in transferrin saturation. ${ }^{(62,}$ 63) These findings indicate that a phlebotomy 'overshot' may have an adverse effect by further reducing hepcidin, with subsequent increase in intestinal absorption of iron. Another study propose upward review of the existing ferritin target (less than $50 \mu \mathrm{g} / \mathrm{L}$ to look for the optimum balance of reduced ferritin and a minimum reduction of hepcidin. ${ }^{(62)}$ Therefore, hepcidin assessments should be determined in further clinical studies. It is not obvious if the targets of phlebotomy may be identified by hepcidin levels or by the hepcidin to ferritin ratio. There are no studies available related to treatment monitoring in another $\mathrm{HH}$ mutation. However, hepcidin is a possible therapeutic aim in haemochromatosis, which may considerably improve the treatment and follow-up of $\mathrm{HH}$ patients, rendering the possible diagnostic utility of hepcidin unclear.

Recently, the association between hepcidin and cancer-related anemia has been studied. This study showed that anaemia is associated with hepcidin overexpression in patients with increased C-reactive protein, suggesting that hepcidin play distinct role in the development of cancer-related anemia. ${ }^{(64)}$

\section{Hepcidin assays}

Developing assays to estimate hepcidin quantity in biological fluids has proven to be challenging. It is difficult to develop antibodies for laboratory tests because hepcidin is an evolutionarily conserved small peptide, which tends to aggregate and adhere to laboratory plastics. ${ }^{(65)}$ However, two major assays have been developed; mass spectrometry and classical immunoassays. ${ }^{(66)}$ Although mass spectrometry-based tests are more costly, they can differentiate between hepcidin isoforms. Immunoassays often lack the specificity of hepcidin 25 and detect total levels of hepcidin. However, the importance of measuring hepcidin 25 specifically rather than total hepcidin for clinical decision-making is debatable.

Absolute hepcidin levels vary considerably (up to 10 fold) between tests in the absence of a main reference material, a reference technique, and a commutable calibrator. ${ }^{(67)}$ While harmonization research are ongoing, these discrepancies now prevent the possibility of comparing the data and establishing of a uniform reference range. ${ }^{(68)}$ Instead, each method/lab should develop strict reference ranges for age and sex, for hepcidin to serum ferritin and hepcidin to transferrin sataration ratios, in addition to that for hepcidin. Till now, only four population studies, two in Italy $(\mathrm{n}=1577, \mathrm{n}=1391) .{ }^{(69,70)}$, one in the Netherlands $(\mathrm{n}=$ 2998). ${ }^{(71)}$ and one in West Africa $(n=1316) .{ }^{(72)}$, have estimated differences in serum hepcidin in the general population, clearly indicating that hepcidin levels increased considerably as the number of metabolic syndrome characteristics increased. ${ }^{(70)}$ Moreover, hepcidin levels are higher in postmenopausal versus premenopausal women and are highly correlated with serum levels of ferritin. ${ }^{69,71)}$ Furthermore, Hepcidin and hepcidin to ferritin ratio were not correlated with atherosclerosis or with cardiovascular disease. ${ }^{(73)}$ Whereas findings from smaller studies revealed that the within-subject variability of hepcidin levels was relatively high. In addition, hepcidin levels were higher in prolonged fasting. ${ }^{(74)}$ and revealed both circadian rhythm and significant variation (27\%-50\%) from day to day. ${ }^{(75)}$ Values of Hepcidin 25 reduce within 1-2 days with storage at room temperature but they remain stable for 1 week, 4 weeks, and 2 years at $4^{\circ} \mathrm{C},-20^{\circ} \mathrm{C}$, and $-80^{\circ} \mathrm{C}$, respectively. ${ }^{(76,77)}$

\section{Conclusions}

Although its excited findings at the beginning, the data about the diagnostic utilizations of hepcidin is remain limited. There have been some advances in measurement of hepcidin-25 quantitatively, but a lot of pre-analytical issues still unanswered. Recently, trials focused on 
hepcidin agonists and antagonists based on their possible therapeutic applications. Now, the question will hepcidin can be use in diagnosis in the future.

\section{References}

1. Kali A, Charles MVP, Seetharam RSK. Hepcidin - A novel biomarker with changing trends. Pharmacogn Rev. 2015;9(17):35-40.

2. Nicolae CD, Coman OA, Ene C, Nicolae I, Fulga I. Hepcidin in neoplastic disease. J Med Life. 2013;6(3):355-60.

3. Reichert C, Marafon F, Levy D, Maselli L, Bagatini M, Blatt S, Bydlowski S, Celso S. Influence of Hepcidin in the Development of Anemia. 2018.

4. Girelli D, Nemeth E, Swinkels DW. Hepcidin in the diagnosis of iron disorders. Blood. 2016;127(23):2809-13.

5. Pagani A, Nai A, Silvestri L, Camaschella C. Hepcidin and Anemia: A Tight Relationship. Front Physiol. 2019;10(1294).

6. Pagani A, Nai A, Silvestri L, Camaschella C. Hepcidin and Anemia: A Tight Relationship. Front Physiol. 2019;10:1294-.

7. Robson KJ. Hepcidin and its role in iron absorption. Gut. 2004,53(5):617-9.

8. Fleming RE, Sly WS. Hepcidin: a putative iron-regulatory hormone relevant to hereditary hemochromatosis and the anemia of chronic disease. Proc Natl Acad Sci U S A. 2001;98(15):8160-2.

9. Ganz T, Nemeth E. Iron imports. IV. Hepcidin and regulation of body iron metabolism. Am J Physiol Gastrointest Liver Physiol. 2006;290(2):G199-203.

10. Ashrafian H. Hepcidin: the missing link between hemochromatosis and infections. Infect Immun. 2003;71(12):6693-700.

11. Lasocki S, Longrois D, Montravers P, Beaumont C. Hepcidin and anemia of the critically ill patient: bench to bedside. Anesthesiology. 2011;114(3):688-94.

12. Cizmeci MN, Kara S, Kanburoglu MK, Simavli S, Duvan CI, Tatli MM. Detection of cord blood hepcidin levels as a biomarker for early-onset neonatal sepsis. Med Hypotheses. 2014;82(3):310-2.

13. Dudkowiak R, Neubauer K, Poniewierka E. Hepcidin and its role in inflammatory bowel disease. Adv Clin Exp Med. 2013;22(4):585-91.

14. Kemna EH, Tjalsma H, Willems HL, Swinkels DW. Hepcidin: from discovery to differential diagnosis. Haematologica. 2008;93(1):90-7.

15. Piperno A, Marian R, Trombini P, Girelli D. Hepcidin modulation in human diseases: from research to clinic. World J Gastroenterol. 2009;15(5):538-51.

16. Camaschella C, Silvestri L. Molecular mechanisms regulating hepcidin revealed by hepcidin disorders. ScientificWorldJournal. 2011;11:1357-66.

17. Ganz T, Olbina G, Girelli D, Nemeth E, Westerman M. Immunoassay for human serum hepcidin. Blood. 2008;112(10):4292-7.

18. Nemeth E, Valore EV, Territo M, Schiller G, Lichtenstein A, Ganz T. Hepcidin, a putative mediator of anemia of inflammation, is a type II acute-phase protein. Blood. 2003;101(7):2461-3.

19. Kemna E, Pickkers P, Nemeth E, van der Hoeven H, Swinkels D. Time-course analysis of hepcidin, serum iron, and plasma cytokine levels in humans injected with LPS. Blood. 2005;106(5):1864-6.

20. Brugnara C. An immunoassay for human serum hepcidin at last: Ganz klar? Blood. 2008;112(10):3922-3.

21. Brugnara C. Iron deficiency and erythropoiesis: new diagnostic approaches. Clin Chem. 2003;49(10):1573-8. 
22. Lozoff B, Jimenez E, Wolf AW. Long-term developmental outcome of infants with iron deficiency. N Engl J Med. 1991;325(10):687-94.

23. Brugnara C, Zurakowski D, DiCanzio J, Boyd T, Platt O. Reticulocyte hemoglobin content to diagnose iron deficiency in children. JAMA. 1999;281(23):2225-30.

24. De Falco L, Totaro F, Nai A, Pagani A, Girelli D, Silvestri L, Piscopo C, Campostrini N, Dufour C, Al Manjomi F, Minkov M, Van Vuurden DG, Feliu A, Kattamis A, Camaschella C, Iolascon A. Novel TMPRSS6 mutations associated with iron-refractory iron deficiency anemia (IRIDA). Hum Mutat. 2010;31(5):E1390-405.

25. Beutler E, Van Geet C, te Loo DM, Gelbart T, Crain K, Truksa J, Lee PL. Polymorphisms and mutations of human TMPRSS6 in iron deficiency anemia. Blood Cells Mol Dis. 2010;44(1):16-21.

26. Theurl I, Aigner E, Theurl M, Nairz M, Seifert M, Schroll A, Sonnweber T, Eberwein L, Witcher DR, Murphy AT, Wroblewski VJ, Wurz E, Datz C, Weiss G. Regulation of iron homeostasis in anemia of chronic disease and iron deficiency anemia: diagnostic and therapeutic implications. Blood. 2009;113(21):5277-86.

27. Tiker F, Celik B, Tarcan A, Kilicdag H, Ozbek N, Gurakan B. Serum pro-hepcidin levels and relationships with iron parameters in healthy preterm and term newborns. Pediatr Hematol Oncol. 2006;23(4):293-7.

28. Ulukol B, Orhon FS, Hanoluk A, Akar N. Serum Pro-Hepcidin Levels and Relationship with Ferritin in Healthy Non-Anaemic Infants. Acta Haematol. 2007;118(2):702.

29. Orhon FS, Ulukol B, Hanoluk A, Akar N. Serum pro-hepcidin levels in infants with iron deficiency anaemia. Int J Lab Hematol. 2008;30(6):546-7.

30. Collard KJ. Iron homeostasis in the neonate. Pediatrics. 2009;123(4):1208-16.

31. Karlsson T. Evaluation of a competitive hepeidin ELISA assay in the differential diagnosis of iron deficiency anaemia with concurrent inflammation and anaemia of inflammation in elderly patients. J Inflanm. 2017;14(1):21.

32. Weiss G, Goodnough LT. Anemia of chronic disease. N Engl J Med. 2005;352(10):1011-23.

33. Kemna EH, Kartikasari AE, van Tits LJ, Pickkers P, Tjalsma H, Swinkels DW. Regulation of hepcidin: insights from biochemical analyses on human serum samples. Blood Cells Mol Dis. 2008;40(3):339-46.

34. Weiss G, Ganz T, Goodnough LT. Anemia of inflammation. Blood. 2019;133(1):40-

50 .

35. Koliaraki V, Marinou M, Vassilakopoulos TP, Vavourakis E, Tsochatzis E, Pangalis GA, Papatheodoridis G, Stamoulakatou A, Swinkels DW, Papanikolaou G, Mamalaki A. A Novel Immunological Assay for Hepcidin Quantification in Human Serum. PLoS One. 2009;4(2):e4581.

36. Yacoub MF, Ferwiz HF, Said F. Effect of Interleukin and Hepcidin in Anemia of Chronic Diseases. Anemia. 2020;2020:3041738-.

37. Lasocki S, Baron G, Driss F, Westerman M, Puy H, Boutron I, Beaumont C, Montravers P. Diagnostic accuracy of serum hepcidin for iron deficiency in critically ill patients with anemia. Intensive Care Med. 2010;36(6):1044-8.

38. Cherian S, Forbes DA, Cook AG, Sanfilippo FM, Kemna EH, Swinkels DW, Burgner DP. An Insight into the Relationships between Hepcidin, Anemia, Infections and Inflammatory Cytokines in Pediatric Refugees: A Cross-Sectional Study. PLoS One. 2008;3(12):e4030.

39. Thomas C, Kobold U, Balan S, Roeddiger R, Thomas L. Serum hepcidin-25 may replace the ferritin index in the Thomas plot in assessing iron status in anemic patients. Int $\mathrm{J}$ Lab Hematol. 2011;33(2):187-93. 
40. Donker AE, Schaap CC, Novotny VM, Smeets R, Peters TM, van den Heuvel BL, Raphael MF, Rijneveld AW, Appel IM, Vlot AJ, Versluijs AB, van Gelder M, Granzen B, Janssen MC, Rennings AJ, van de Veerdonk FL, Brons PP, Bakkeren DL, Nijziel MR, Vlasveld LT, Swinkels DW. Iron refractory iron deficiency anemia: a heterogeneous disease that is not always iron refractory. Am J Hematol. 2016;91(12):E482-e90.

41. Heeney MM, Guo D, De Falco L, Campagna DR, Olbina G, Kao PP-C, Schmitz-Abe K, Rahimov F, Gutschow P, Westerman K, Ostland V, Jackson T, Klaassen RJ, Markianos K, Finberg KE, Iolascon A, Westerman M, London WB, Fleming MD. Normalizing hepcidin predicts TMPRSS6 mutation status in patients with chronic iron deficiency. Blood. 2018;132(4):448-52.

42. Sørensen E, Rigas AS, Didriksen M, Burgdorf KS, Thørner LW, Pedersen OB, Hjalgrim H, Petersen MS, Erikstrup C, Ullum H. Genetic factors influencing hemoglobin levels in 15,567 blood donors: results from the Danish Blood Donor Study. Transfusion (Paris). 2019;59(1):226-31.

43. Brugnara C, Colella GM, Cremins J, Langley RC, Jr., Schneider TJ, Rutherford CJ, Goldberg MA. Effects of subcutaneous recombinant human erythropoiein in normal subjects: development of decreased reticulocyte hemoglobin content and iron-deficient erythropoiesis. J Lab Clin Med. 1994;123(5):660-7.

44. Coyne D. Iron indices: what do they really mean? Kidney Int Suppl. 2006(101):S4-8. 45. Katodritou E, Zervas K, Terpos E, Brugnara C. Use of erythropoiesis stimulating agents and intravenous iron for cancer and treatment-related anaemia: the need for predictors and indicators of effectiveness has not abated. Br J Haematol. 2008;142(1):3-10.

46. Wish JB. Assessing iron status: beyond serum ferritin and transferrin saturation. Clin J Am Soc Nephrol. 2006;1 Suppl 1:S4-8.

47. Nakanishi T, Kimura T, Kuragano T. The Hepcidin-Anemia Axis: Pathogenesis of Anemia in Chronic Kidney Disease. Contrib Nephrol. 2019;198:124-34.

48. Li H, Rose MJ, Tran L, Zhang J, Miranda LP, James CA, Sasu BJ. Development of a method for the sensitive and quantitative determination of hepcidin in human serum using LC-MS/MS. J Pharmacol Toxicol Miethods. 2009;59(3):171-80.

49. Ashby DR, Gale DP, Busbridge M, Murphy KG, Duncan ND, Cairns TD, Taube DH, Bloom SR, Tam FW, Chapman RS, Maxwell PH, Choi P. Plasma hepcidin levels are elevated but responsive to erythropoietin therapy in renal disease. Kidney Int. 2009;75(9):976-81.

50. Zaritsky J, Young B, Wang H-J, Westerman M, Olbina G, Nemeth E, Ganz T, Rivera S, Nissenson AR, Salusky IB. Hepcidin--a potential novel biomarker for iron status in chronic kidney disease. Clinical journal of the American Society of Nephrology : CJASN. 2009;4(6):1051-6.

51. Babitt JL, Lin HY. Molecular mechanisms of hepcidin regulation: implications for the anemia of CKD. Am J Kidney Dis. 2010;55(4):726-41.

52. Peters HP, Laarakkers CM, Swinkels DW, Wetzels JF. Serum hepcidin-25 levels in patients with chronic kidney disease are independent of glomerular filtration rate. Nephrol Dial Transplant. 2010;25(3):848-53.

53. Weiss G, Theurl I, Eder S, Koppelstaetter C, Kurz K, Sonnweber T, Kobold U, Mayer G. Serum hepcidin concentration in chronic haemodialysis patients: associations and effects of dialysis, iron and erythropoietin therapy. Eur J Clin Invest. 2009;39(10):883-90.

54. Kato A, Tsuji T, Luo J, Sakao Y, Yasuda H, Hishida A. Association of prohepcidin and hepcidin-25 with erythropoietin response and ferritin in hemodialysis patients. Am $\mathrm{J}$ Nephrol. 2008;28(1):115-21.

55. Costa E, Swinkels DW, Laarakkers CM, Rocha-Pereira P, Rocha S, Reis F, Teixeira F, Miranda V, do Sameiro Faria M, Loureiro A, Quintanilha A, Belo L, Santos-Silva A. 
Hepcidin Serum Levels and Resistance to Recombinant Human Erythropoietin Therapy in Haemodialysis Patients. Acta Haematol. 2009;122(4):226-9.

56. Swinkels DW, Wetzels JF. Hepcidin: a new tool in the management of anaemia in patients with chronic kidney disease? Nephrol Dial Transplant. 2008;23(8):2450-3.

57. Swinkels DW, Drenth JP. Hepcidin in the management of patients with mild nonhemochromatotic iron overload: Fact or fiction? J Hepatol. 2008;49(5):680-5.

58. Alexander J, Kowdley KV. HFE-associated hereditary hemochromatosis. Genet Med. 2009;11(5):307-13.

59. Swinkels DW, Janssen MC, Bergmans J, Marx JJ. Hereditary hemochromatosis: genetic complexity and new diagnostic approaches. Clin Chem. 2006;52(6):950-68.

60. Nemeth E. Hepcidin in beta-thalassemia. Ann N Y Acad Sci. 2010;1202:31-5.

61. EASL clinical practice guidelines for HFE hemochromatosis. J Hepatol. 2010;53(1):3-

22.

62. Piperno A, Girelli D, Nemeth E, Trombini P, Bozzini C, Poggiali E, Phung Y, Ganz T, Camaschella C. Blunted hepcidin response to oral iron challenge in HFE-related hemochromatosis. Blood. 2007;110(12):4096-100.

63. Bozzini C, Campostrini N, Trombini P, Nemeth E, Castagna A, Tenuti I, Corrocher R, Camaschella C, Ganz T, Olivieri O, Piperno A, Girelli D. Measurement of urinary hepcidin levels by SELDI-TOF-MS in HFE-hemochromatosis. Blood Cells Mol Dis. 2008;40(3):34752.

64. Cheng Z, Yan M, Lu Y, Pan X-T. Expression of serum BMP6 and hepcidin in cancerrelated anemia. Hematology. 2020;25(1):134-8.

65. Hunter HN, Fulton DB, Ganz T, Vogel HJ. The solution structure of human hepcidin, a peptide hormone with antimicrobial activity that is involved in iron uptake and hereditary hemochromatosis. J Biol Chem. 2002;277(40):3759\%-603.

66. Kroot JJ, Laarakkers CM, Geurts-Moespot AJ, Grebenchtchikov N, Pickkers P, van Ede AE, Peters HP, van Dongen-Lases E, Wetzels JF, Sweep FC, Tjalsma H, Swinkels DW. Immunochemical and mass-spectrometry-based serum hepcidin assays for iron metabolism disorders. Clin Chem. 2010;56(10):1570-9.

67. Kroot JJ, van Herwaarden AE, Tjalsma H, Jansen RT, Hendriks JC, Swinkels DW. Second round robin for plasma hepcidin methods: first steps toward harmonization. Am J Hematol. 2012;87(10):977-83.

68. van der Vorm LN, Hendriks JC, Laarakkers CM, Klaver S, Armitage AE, Bamberg A, Geurts-Moespot AJ, Gireli D, Herkert M, Itkonen O, Konrad RJ, Tomosugi N, Westerman M, Bansal SS, Campostrini N, Drakesmith H, Fillet M, Olbina G, Pasricha SR, Pitts KR, Sloan JH, Tagliaro F, Weykamp CW, Swinkels DW. Toward Worldwide Hepcidin Assay Harmonization: Identification of a Commutable Secondary Reference Material. Clin Chem. 2016;62(7):993-1001.

69. Traglia M, Girelli D, Biino G, Campostrini N, Corbella M, Sala C, Masciullo C, Viganò F, Buetti I, Pistis G, Cocca M, Camaschella C, Toniolo D. Association of HFE and TMPRSS6 genetic variants with iron and erythrocyte parameters is only in part dependent on serum hepcidin concentrations. J Med Genet. 2011;48(9):629-34.

70. Martinelli N, Traglia M, Campostrini N, Biino G, Corbella M, Sala C, Busti F, Masciullo C, Manna D, Previtali S, Castagna A, Pistis G, Olivieri O, Toniolo D, Camaschella C, Girelli D. Increased serum hepcidin levels in subjects with the metabolic syndrome: a population study. PLoS One. 2012;7(10):e48250-e.

71. Galesloot TE, Vermeulen SH, Geurts-Moespot AJ, Klaver SM, Kroot JJ, van Tienoven D, Wetzels JF, Kiemeney LA, Sweep FC, den Heijer M, Swinkels DW. Serum hepcidin: reference ranges and biochemical correlates in the general population. Blood. 2011;117(25):e218-25. 
72. Jallow MW, Campino S, Prentice AM, Cerami C. Association of common TMPRSS6 and $\mathrm{TF}$ gene variants with hepcidin and iron status in healthy rural Gambians. Sci Rep. 2021;11(1):8075.

73. Pechlaner R, Kiechl S, Mayr M, Santer P, Weger S, Haschka D, Bansal SS, Willeit J, Weiss G. Correlates of serum hepcidin levels and its association with cardiovascular disease in an elderly general population. Clin Chem Lab Med. 2016;54(1):151-61.

74. Troutt JS, Rudling M, Persson L, Ståhle L, Angelin B, Butterfield AM, Schade AE, Cao G, Konrad RJ. Circulating human hepcidin-25 concentrations display a diurnal rhythm, increase with prolonged fasting, and are reduced by growth hormone administration. Clin Chem. 2012;58(8):1225-32.

75. Kroot JJ, Hendriks JC, Laarakkers CM, Klaver SM, Kemna EH, Tjalsma H, Swinkels DW. (Pre)analytical imprecision, between-subject variability, and daily variations in serum and urine hepcidin: implications for clinical studies. Anal Biochem. 2009;389(2):124-9. 76. Itkonen O, Parkkinen J, Stenman UH, Hämäläinen E. Preanalytical factors and reference intervals for serum hepcidin LC-MS/MS method. Clin Chim Acta. 2012;413(78):696-701.

77. Laarakkers CM, Wiegerinck ET, Klaver S, Kolodziejczyk M, Gilie H, Hohlbaum AM, Tjalsma H, Swinkels DW. Improved mass spectrometry assay for plasma hepcidin: detection and characterization of a novel hepcidin isoform. PLoS One. 2013;8(10):e75518. 